rõ ràng việc sử dụng dung dịch nước súc miệng HMU Chlorhexidine là tốt hơn về hiệu quả. Trong nghiên cứu, có thể thây các đối tượng được hướng dẫn tỉ mỉ về cách vệ sinh răng miệng và sử dụng các loại nước súc miệng theo khuyến cáo của nhà sản xuất và giám sát liên tục, được kiểm soát mảng bám răng qua việc vệ sinh răng miệng cá nhân tại nhà chủ yếu bằng chải răng đúng cách và sử dụng chỉ tơ, bàn chải kẽ nên ý thức và hành vi vệ sinh được cải thiện tốt hơn, không để tình trạng vệ sinh không tốt ảnh hưởng đến kết quả điều trị. Cũng nhờ việc kiểm soát vệ sinh tốt mà kết quả của nghiên cứu của chúng tôi khả quan.

Sau điều trị 2 tuần, 4 tuần, các chỉ số: chỉ số lợi GI, chỉ số vệ sinh răng miệng đơn giản $\mathrm{OHI}-\mathrm{S}$, chỉ số chảy máu lợi khi thăm dò (BOP) được cải thiện rõ rệt so với trước điều trị, với hiệu quả tốt hơn do với nước muối đơn thuần.

\section{KẾT LUÂN}

Qua nghiên cứu và phân tích các kết quả điều trị cho 178 sinh viên năm thứ nhất tại trường Đại học Y Hà Nội chúng tôi rút ra các kết luận sau:

- Tỉ lệ bệnh nhân chảy máu lợi khi thăm khám ở nhóm can thiệp là $87,6 \%$, và ở nhóm chứng là $84,3 \%$.
- Nước súc miệng HMU Chlorhexidine 0,12\% có tác dụng cải thiện các chỉ số quanh răng, hỗ trợ điều trị viêm lợi với hiệu quả tốt hơn so với nước muối sinh lý đơn thuần.

\section{TÀI LIẸU THAM KHẢO}

1. Trân Văn Trường, Trịnh Đình Hải, A John Spencer và cs (2001): Điều tra sức khỏe răng miêng toàn quốc. Nhà xuất bản $Y$ hoc, : p. 69-75.

2. Nguyễn Bích Vân (2017). So sánh hiêuu quả của thuốc súc miệng GIVALEX(r) và ELUDRIL(r) đối với mảng bám, viêm nướu va vết dính trên răng. $Y$ Học TP. Hồ Chí Minh.11, số 2

3. Mariotti A (1999). Dental plaque-induced gingival diseases. Annals of Periodontology 4, p. 7-19.

4. James $P$, Worthington HV, Parnell $C$ và $C S$ (2017). Chlorhexidine mouthrinse as an adjunctive treatment for gingival health. Cochrane Database Syst Rev, p: 3-6.

5. Armitage, G.C (1999). Development of a classification system for periodontal diseases and conditions. Ann Periodontol, 1999. 4(1): p. 1-6.

6. No authors (2015) American Academy of Periodontology Task Force Report on the Update to the 1999 Classification of Periodontal Diseases and Conditions. J Periodontol. 86(7): p. 835-8.

7. David Herrera (2013). Chlorhexidine mouthwash reduces plaque and gingivitis. Evid Based Dent.14(1):17-8.

8. Richards D (2017). Chlorhexidine mouthwash plaque levels and gingival health. Evid Based Dent. $18,37-38$.

\title{
ĐĂC ĐIỂM NHÂN CÁCH BỆNH CỦA CO GIẬT CHỨC NĂNG
}

\section{TÓM TẮT}

Mục tiêu: Tìm hiểu đặc điểm lâm sàng và nhân cách ở bệnh nhân co giật chức năng. Phương pháp nghiên cứu: Phân tích về đặc điểm lâm sàng và nhân cách ở 51 bênh nhân co giật chức năng được điều trị tại Khoa Tâm thần, Bệnh viện Quân y 103. Kết quả nghiên cứu: Lâm sàng của bệnh nhân co giật chức năng rất đa dạng và phong phú. Một tỷ lệ cao bệnh nhân rối loạn phân ly có xu hướng nhân cách không ổn định $(82,41 \%)$ và $63,89 \%$ bệnh nhân xu hướng nhân cách hướng ngoai theo trắc nghiêm tâm lý Eysenck. Ngoài ra bệnh nhân có thang trẩm cảm $(68,63 \%)$, thang nghi bênh $(62,75 \%)$ và thang phân ly $(56,86 \%)$ theo trắc nghiệm tâm lý MMPI. Do vậy có thể sử dụng trắc nghiệm tâm lý Eysenck và

\footnotetext{
${ }^{1}$ Bệnh viện Quân y 103-Học viện Quân y ${ }^{2}$ Học viện Quân y

Chịu trách nhiệm chính: Đinh Việt Hùng

Email: bshunga6@gmail.com

Ngày nhận bài: 10.5.2021

Ngày phản biện khoa học: 25.6.2021

Ngày duyệt bài: 7.7.2021
}

Đinh Việt Hùng ${ }^{1}$, Hoàng Xuân Cường ${ }^{2}$ MMPI làm tài liệu tham khảo để đánh giá tính cách phân ly ở bệnh nhân RLPL vận động và cảm giác. Kết luận: Kết quả nghiên cứu này đưa ra gợi ý rằng trắc nghiệm tâm lý Eysenck và MMPI là phương pháp dùng để đánh giá tính cách phân ly ở bệnh nhân co giật chức năng.

Tư khóa: Nhân cách bệnh, co giật chức năng.

\section{SUMMARY \\ SICK PERSONALITIES CHARACTERISTICS OF PATIENTS WITH DISSOCIATIVE CONVULSIONS}

Objective: To study the clinical manifestations and sick personalities of patients with dissociative convulsions. Methods: Analyse the clinical manifestations and personality of 51 patients with dissociative convulsions who treated in Psychiatry Department, 103 Military Hospital. Results: The clinical features of patients with dissociative convulsions are diverse and varied. A high proportion of dissociative patients tend to have unstable personalities $(82.41 \%)$ and $63.89 \%$ of patients have extroved according to Eysenck psychometric test. In addition, the patient had a depression scale $(68.63 \%)$, a suspicion scale $(62.75 \%)$ and a dissociation scale 
(56.86\%) according to the MMPI psychological test. Therefore, the Eysenck test and MMPI can be used as references to assess dissociative personality in patients with motor and sensory dissociation disorders. Conlusion: The results of this study suggest that Eysenck and MMPI psychometric tests are methods used to assess dissociative personality in patients with dissociative convulsions.

Keywords: Sick personalities, dissociative convulsions

\section{I. ĐĂT VẤN ĐỀ}

Rối loạn phân ly là một rối loạn chức năng có liên quan chặt chẽ với sang chấn tâm lý và nhân cách người bệnh. Trong đó co giật chức năng chiếm tỷ lệ cao dao động từ 0,023-0,058\% dân số do tăng trưởng kinh tế, công nghiệp hóa, hiện đại hóa, đô thị hóa...Bệnh cảnh lâm sàng co giật chức năng rất đa dạng và phong phú gây khó khăn cho chẩn đoán và điều trị. Ớ nước ta việc nghiên cứu về co giật chức năng chưa đước đồng bộ và hệ thống. Việc chẩn đoán và nhận biết sớm các nét tính cách của co giật chức năng góp phần nâng cao việc điều trị và phòng bệnh. Vì vậy, chúng tôi thực hiện nghiên cứu với mục tiêu: Mô tả đặc điểm nhân cách bệnh của co giật chức năng.

\section{II. ĐỐI TƯợNG VÀ PHƯƠNG PHÁP NGHIÊN CỨU}

2.1. Đối tượng nghiên cứu. Đối tượng nghiên cứu gồm 51 bệnh nhân đáp ứng đây đủ tiêu chuẩn chẩn đoán co giật chức năng theo ICD-10 điều trị nọi trú tai Khoa Tâm thần-Bênh viện Quân y 103 từ tháng 5/2019 đến tháng $5 / 2021$.

2.2. Phương pháp nghiên cứu. Sử dụng phương pháp nghiên cứu hồi cứu mô tả cắt ngang, phân tích đánh giá từng trường hợp cụ thể. Các triệu chứng lâm sàng được đánh giá trong ngày đầu bệnh nhân vào viện, việc đánh giá được tiến hành độc lập bởi hai bác sĩ chuyên nghành tâm thần.

\subsection{Phân tích số liệu}

Phân tích số liệu được tiến hành trên phần mềm phân tích số liệu SPSS 20.0. Sự khác biệt có ý nghĩa thống kê được xác định cho các kiểm định với mức $p<0,05$.

\section{KẾT QUẢ NGHIÊN CỨU}

\section{1. Đặc điểm chung của đối tượng} nghiên cứu

Bảng 3.1. Đặc điểm nhóm tuổi của bệnh nhân nghiên cứu

\begin{tabular}{|c|c|c|}
\hline Nhóm tuối & $\begin{array}{c}\text { Cổ thống kế lươnng } \\
\text { (n) }\end{array}$ & $\begin{array}{c}\text { Tỷ lệ } \\
\text { (\%) }\end{array}$ \\
\hline$<20$ & 35 & 68,63 \\
\hline $20-29$ & 13 & 25,49 \\
\hline
\end{tabular}

\begin{tabular}{|c|c|c|}
\hline$>30$ & 3 & 5,88 \\
\hline Tuổi trung bình & $21,28 \pm 10,53$ \\
\hline
\end{tabular}

Trong nghiên cứu của chúng tôi thấy rằng nhóm tuổi bị co giật chức năng cao nhất là nhóm $<20$ tuổi $(68,63 \%)$ và thấp nhất là nhóm >30 tuổi $(5,88 \%)$. Nhóm tuổi 18-20 là nhóm tuổi học tập và lao động, đặc biệt đây là lứa tuổi tham gia nghĩa vụ quân sự nền có sự thay đổ lớn về môi trường sinh hoạt từ tự do sang kỷ luật, từ sự quan tâm của guia đình sang sự tự lập và chấp hành kỷ cương dẫn đến các sang chấn và chất lượng cuộc sống thay đổi. Kết quả nghiên cứu của chúng tôi phù hợp với nghiên cứu của nhiều tác giả trên thế giới, khi khẳng định rằng các bệnh nhân co giật chức năng đa số là những thanh niên tuổi trên dưới 20 có nhiều thay đổi tâm sinh lý nhất, công với họ không có nhiều kinh nghiệm sống dấn đến khó thích nghi kịp với các thay đổi đó [1].

Bảng 3.2. Đặc điểm về giới tính của bệnh nhân nghiên cứu

\begin{tabular}{|c|c|c|}
\hline Giới tính & $\begin{array}{c}\text { Chỉ số thống kêợng } \\
\text { (n) }\end{array}$ & $\begin{array}{c}\text { Tỷ lệ } \\
\text { (\%) }\end{array}$ \\
\hline Nam & 32 & 62,75 \\
\hline Nữ & 19 & 37,25 \\
\hline
\end{tabular}

Kết quả bảng 3.2 chỉ ra rằng tỷ lê bênh nhân nam chiếm tỷ lệ cao nhất với $62,75 \%$ và tỷ lệ nữ giới chiếm $37,25 \%$. Tỷ lệ nam/nữ là $1,7 / 1$. Kết quả nghiên cứu của chúng tôi khác với các nghiên cứu khác như nghiên cứu của Boisclair D.J. (2020) chỉ ra rằng bệnh nhân nữ nhiều hơn bệnh nhân nam với tỷ lệ nữ/nam là $3,25 / 1$. Sự khác nhau này bởi nghiên cứu của chúng tổi thực hiện tại Bệnh viện Quân y 103 là nơi điều trị cho các nam quan nhân mắc bênh lý tâm thần chính vì vậy số lượng bệnh nhân nam sẽ cao hơn [2].

Bảng 3.3. Đặc điểm về nghề nghiệp của bênh nhân nghiên cứu

\begin{tabular}{|c|c|c|}
\hline Giới tính & $\begin{array}{c}\text { Chỉ số thống kế lượng } \\
\text { (n) }\end{array}$ & $\begin{array}{c}\text { Tỷ lệ } \\
\text { (\%) }\end{array}$ \\
\hline Bộ đội & 33 & 64,71 \\
\hline Cán bộ viên chức & 2 & 3,92 \\
\hline Công nhân & 4 & 7,84 \\
\hline Học sinh, sinh viên & 9 & 17,65 \\
\hline Nghề khác & 3 & 5,88 \\
\hline
\end{tabular}

Về nghề nghiệp Bảng 3.3 cho thấy bệnh nhân là bộ đội chiếm tỷ lệ cao nhất với $61,47 \%$, tiếp đến bệnh nhân làm là học sinh, sinh viên chiếm $17,65 \%$; còn các nghề ngiệp khác dao động từ 3,92\%-7,84\%. Như vậy nghề nghiệp của bệnh nhân co giật chức năng cũng đa dạng, bao phủ nhiều lĩnh vực của đời sống. trong đó bộ đội, học 
sinh và sinh viên có tỷ lệ lớn, điều này được giải thích bởi đó là 2 nghành nghề có sự thay đổi, khác biệt nhất nếu không có sự thích nghi phù hợp [3].

3.2. Đặc điểm co giật chức năng đối tượng nghiên cứu

Bảng 3.4. Đặc điểm về hoàn cảnh khởi phát co giật chức năng

\begin{tabular}{|c|c|c|}
\hline Hoàn cảnh & $\begin{array}{c}\text { Chí thống kế lượng } \\
\text { (n) }\end{array}$ & $\begin{array}{c}\text { Tỷ lệ } \\
\text { (\%) }\end{array}$ \\
\hline $\begin{array}{c}\text { Sang chấn tâm lý } \\
\text { Không có sang chấn } \\
\text { tâm lý }\end{array}$ & 43 & 84,31 \\
\hline
\end{tabular}

Hoàn cảnh khởi phát cớn co giật chức năng sau sang chấn tâm lý chiếm tỷ lệ cao nhất 84,31\%; còn lại số ít bệnh nhân có cơn co giật chức năng không liên quan đến sang chấn tâm lý: 15,69\%. Kết quả nghiên cứu của chúng tôi phù hợp với nghiên cứu Doernberg $\mathrm{E}$ (2016) khi nhận định rằng bệnh nhân co giật chức năng đều có mối liên quan đến sang chẩn tâm lý như sự thay đổi của môi trường sinh hoạt, không thành công trong sự nghiệp, các bạo hành về tinh thần...[4].

Bảng 3.5. Đặc điểm triệu chứng co giật toàn thần ở bênh nhần nghiên cứu

\begin{tabular}{|c|c|c|}
\hline Triệu chứng & $\begin{array}{c}\text { Cố thống kế lượng } \\
\text { (n) }\end{array}$ & $\begin{array}{c}\text { Tỳ lệ } \\
\text { (\%) }\end{array}$ \\
\hline Định hình & 12 & 23,53 \\
\hline Không định hình & 39 & 76,47 \\
\hline
\end{tabular}

Đặc điểm thường thấy là các cơn co giật khởi đầu một cách từ từ và kết thúc từ từ khổng có các giai đoạn co cứng, co giật, doãi mềm và hôn mê của một cớn co giật toàn thể trong động kinh cơn lớn. Trong cơn bệnh nhân không mất ý thức, nhớ hết sự việc xảy ra trước cơn, trong cơn và sau cơn. Bên cạch đó hình thái co giật chức năng chủ yếu là co giật toàn thân không có tính chất định hình $(76,47 \%)$ với các biểu hiện phong phú như co cứng toàn thân, mắt trớn ngược, giật chân, giật tay. Số ít cơn co giật chức năng diễn ra tại một số bộ phận của người bệnh như tay, chân, đâu cổ mặt...giống như cơn động kinh cục bộ. Tất cả các bệnh nhân co giật phân ly đều hết cơn hoặc giảm cơn khi khổng có sự quan tâm và chú ý của người xunh quanh [5].

Bảng 3.6. Đặc điểm triệu chứng co giật cuc bộ ở bệnh nhân nghiên cứu

\begin{tabular}{|c|c|c|}
\hline Triệu chứng thống kế & $\begin{array}{c}\text { Số lượng } \\
\text { (n) }\end{array}$ & $\begin{array}{c}\text { Tỷ lệ } \\
\text { (\%) }\end{array}$ \\
\hline Vùng đâu mặt cố & 3 & 14,29 \\
\hline Tay & 11 & 52,38 \\
\hline Chân & 7 & 33,33 \\
\hline \multicolumn{2}{|c|}{}
\end{tabular}

Trong nghiên cứu của chúng tôi, triệu chứng co giật toàn thân là hay gặp nhất $58,82 \%$; còn co giật cục bộ chiếm $41,18 \%$. Đối với cớn co giật cục bộ thì Bảng 3.7 cho thây bệnh nhân có cơn co giật cục bộ ở chi trên là $11 / 21$ chiếm 52,38\%; tiếp đến là bệnh nhân có cơn co giật cục bộ ở chi dưới: $7 / 21$ chiếm $33,33 \%$ và số bệnh nhân có cơn co giật cục bộ ở vùng đầu mặt cổ $3 / 21$ chiếm 14,29\%. Các nghiên cứu trước đây ít đề cập đến cơn co giật chức năng, họ chỉ đề cập đến các rối loạn phân ly như liệt, mù điếc và đau kèm theo các ảo giác đi kèm. Ngày nay hình thái lâm sàng của rối loạn phân ly đã thay đổi điều đó phản ánh các sang chấn trong cuộc sống của bệnh nhân đã thay đổi, họ chịu nhiêu áp lực hơn, môi trường sinh hoat thì thay đổi theo chiều hướng bất lợ cho họ. Triệu chứng co giật cục bộ với đặc điểm: không có rối loạn ý thức, cơn thường xảy ra lúc thức khi lao động và học tập. Điều khác biệt với cơn co giật động kinh cục bộ là thời gian cơn kéo dài và sự kết thúc cơn từ từ [6].

Bảng 3.7. Đặc điểm thời gian co giật ở bệnh nhân nghiên cứu

\begin{tabular}{|c|c|c|}
\hline Thời gian & $\begin{array}{c}\text { Cố lướn thống kếng } \\
\text { (n) }\end{array}$ & $\begin{array}{c}\text { Tỷ lệ } \\
\text { (\%) }\end{array}$ \\
\hline$<10$ phút & 3 & 5,88 \\
\hline $10-20$ phút & 19 & 37,26 \\
\hline $21-30$ phút & 24 & 47,06 \\
\hline$>30$ phút & 5 & 9,80 \\
\hline Thời gian trung bình & $23,47 \pm 12,16$ \\
\hline
\end{tabular}

Bảng 3.7 cho thấy thời gian diễn ra cớn co giật chức năng trung bình là $23,47 \pm 12,16$ phút, trong đó thời gian từ 21-30 phút diễn ra cớn co giật chức năng là nhiều nhất $24 / 51$ bệnh nhân chiếm $47,06 \%$ và thời gian cơn trên 30 phút là $5 / 51$ chiếm $9,8 \%$. Đây là điểm khác biêt nhất của cơn co giật chức năng so với cơn động kinh, thời gian cơn động kinh thường chỉ kéo dài 2-3 phút [6].

\section{3. Đặc điểm nhân cách bệnh của đối} tượng nghiên cứu

Bảng 3.8. Đặc điểm các sang chấn tâm lý ở bệnh nhân nghiển cứu

\begin{tabular}{|c|c|c|}
\hline Sang chấn tâm lŷ́ số thống kế Số lượng & $\begin{array}{c}\text { Tỷ lệ } \\
\text { (n) } \\
\text { (\%) }\end{array}$ \\
\hline Sang chấn trong gia đình & 11 & 25,58 \\
\hline Sang chấn trong công việc & 18 & 41,86 \\
\hline Sang chấn trong xã hội & 7 & 16,28 \\
\hline Sang chẫn bệnh lý cơ thể & 5 & 11,63 \\
\hline Sang chấn khác & 2 & 4,65 \\
\hline
\end{tabular}

Kết quả Bảng 3.8 cho thấy sang chấn tâm lý gặp nhiêuu nhất là các sang chấn trong công việc $(41,86 \%)$, tiếp đó là sang chấn trong gia đình 
(25,58\%). Các sang chấn trong công việc như thay đổi bất lợi về môi trường công việc, thất bại trong công việc, không đáp ứng sự kỳ̀ vọng của gia đình và những người thân xung quang. Trong khi đó sang chấn trong gia đình là những mâu thuẫn trong sinh hoạt giữa các thành viên trong gia đình, hay là sự khác biệt giữa các thế hệ với nhau. Kết quả nghiên cứu của chúng tôi phù hợp nghiên cứu của Dayan J. (2010) khi thấy các sang chấn về gia đình và công việc là hay gặp nhất đó là sự thay đổi môi trường công việc, sự khà hắc của sự nghiệp cũng như cá nhân hóa trong môi trường gia đình... [7].

Bảng 3.9. Đặc điểm tính cách ở thời niên thiếu của bệnh nhân nghiên cứu

\begin{tabular}{|c|c|c|}
\hline Triệu chứng số thống kế & $\begin{array}{c}\text { Số lượng } \\
\text { (n) }\end{array}$ & $\begin{array}{c}\text { Tỷ lệ } \\
\text { (\%) }\end{array}$ \\
\hline Yếu đuối & 27 & 52,94 \\
\hline Khó hòa đồng & 7 & 13,73 \\
\hline
\end{tabular}

Trong nghiên cứu của chúng tôi thây rằng trong quá trình trưởng thành của cá nhân người bệnh thì có tới $52,94 \%$ bệnh nhân có nét tính cách yếu như là hiền khô, hay khóc, mít ướt, thường xuyên bị mọi người bắt nạt, ít có phản kháng tự vệ của bẻn thân. Có tới 13,73\% bệnh nhân khó hòa đồng, ít giao tiếp tạo nên khoảng cách với mọi người. Tính cách này ảnh hưởng rất lớn tới quá trình hoàn thiện bản thân sau này của bệnh nhân [7].

Bảng 3.10. Đặc điểm tính cách của bệnh nhân nghiên cứu

\begin{tabular}{|c|c|c|}
\hline $\begin{array}{c}\text { Chỉ số thống kê } \\
\text { Nét tính cách }\end{array}$ & $\begin{array}{c}\text { Số lượng } \\
\text { (n) }\end{array}$ & $\begin{array}{c}\text { Tỷ lệ } \\
\text { (\%) }\end{array}$ \\
\hline Cới mớ & 36 & 70,59 \\
\hline Nhút nhát & 29 & 56,86 \\
\hline Đại khái & 31 & 60,78 \\
\hline Tự tin & 21 & 41,18 \\
\hline Vồ tâm & 11 & 21,57 \\
\hline
\end{tabular}

Còn tại thời điểm hiện tại các nét tính cách cảu bệnh nhân rất đa dạng phong phú, thể hiện sự đa chiều, khác biệt ở nhiều thời điểm của bệnh nhân. Các nét tính cách hay gặp lần lượt là cởi mở, nhút nhát, đại khái với 70,59\%, 56,86\% và $60,78 \%$. Chính nét tính cách này là cho bệnh nhân dễ bị tổn thương, mềm yếu trước mọi người, luôn mong chờ sự che trở, bảo vệ của người xung quang. Nét tính đó tạo thành chuỗi cảm xúc, thái độ của bệnh nhân đối với các hoạt động trong cuốc sống.

Bảng 3.11. Đặc điểm các nét tính cách phân ly trên lâm sàng

\begin{tabular}{|c|c|c|}
\hline Nét tính cách số thống kê & $\begin{array}{c}\text { Số lượng } \\
\text { (n) }\end{array}$ & $\begin{array}{c}\text { Tỷ lệ } \\
\text { (\%) }\end{array}$ \\
\hline Dế xúc động & 39 & 76,47 \\
\hline Dế bị ám thị & 41 & 80,39 \\
\hline Thích màu sắc sặc sõ & 14 & 27,45 \\
\hline Thích làm trung tâm & 42 & 82,35 \\
\hline Thích phô trương & 21 & 41,18 \\
\hline Nóng tính & 19 & 37,25 \\
\hline
\end{tabular}

Bảng 3.11 thể hiện nét tính cách phân ly lâm sàng của bệnh nhân co giật chức năng. Bệnh nhân thể hiện cảm xúc dế bị thay đổi như dễ mủi lòng, cả ti, đồng cảm hay chảy nước mắt. Trong đó nét tính cách thích làm trung tâm $(82,35 \%)$, dễ bị ám thị $(80,39 \%)$ và dễ xúc động $(76,47 \%)$ là 3 nét tính cách cốt lõi thể hiện phân ly ở bệnh nhân co giật chức năng. Số ít bệnh nhân thích phô trương (41,18\%), nóng tính $(37,25 \%)$ và thích màu sắc sặc sõ̃ $(27,45 \%)$ đã làm thêm sự đa dạng của nét tính cách phân ly trên lâm sàng [7].

Bảng 3.12. Kết quả trắc nghiệm tâm lý Eysenck

\begin{tabular}{|c|c|c|c|c|}
\multirow{2}{*}{$\begin{array}{c}\text { Chỉ số thống } \\
\text { kết tính cách }\end{array}$} & \multicolumn{2}{|c|}{ Ổn định } & \multicolumn{2}{c|}{$\begin{array}{c}\text { Không ốn } \\
\text { định }\end{array}$} \\
\cline { 2 - 5 } & SL & Tỷ lệ & SL & Tỷ lệ \\
\hline Hướng ngoại & 7 & 13,73 & 21 & 41,18 \\
\hline Hướng nội & 6 & 11.76 & 17 & 33,33 \\
\hline
\end{tabular}

Với trắc nghiêm tâm lý Eysenck thì bệnh nhân co giật chức năng có chức năng hướng ngoại cao nhất với 28 bệnh nhân (54,90\%), còn bệnh nhân hướng nội có 23 bệnh nhân $(45,10 \%)$. Trong đó nét tính cách khổng ổn định chiếm tỷ lệ cao 38 bệnh nhân $(74,51 \%)$ so với 13 bệnh nhân (25,49\%). Tính cách không ổn định theo thang điểm Eysenck là nét tính cách dễ xúc động, mất bình tĩnh, thay đổi thất thường và suy nghĩ nông cạn. Chính vì nét tính cách này mà biểu hiện lâm sàng của bệnh nhân co giật chức năng về mă̆t cảm xúc rất phong phú, đa dạng như biểu hiện cảm xúc bùng nổ, lây lan kiểu dây truyền, diễn ra mạnh mẽ ở không gian hẹp...làm cho bệnh nhân thiếu kiên nhẫn, nóng nảy hơn các nhóm bệnh khác [8].

Bảng 3.13. Đặc điểm nhân cách theo MMPI

\begin{tabular}{|c|c|c|c|c|c|c|}
\hline \multirow{2}{*}{ Thang điểm } & \multicolumn{2}{c|}{ Bình thớ thống kềng } & \multicolumn{2}{c|}{ Ranh giới } & \multicolumn{2}{c|}{ Bệnh lý } \\
\cline { 2 - 7 } & SL & Tỷ lệ & SL & Tỷ lệ & SL & Tỷ lệ \\
\hline Nghi bệnh & 4 & 7,84 & 15 & 29,41 & 32 & 62,75 \\
\hline Trầm cảm & 2 & 3,92 & 14 & 27,45 & 35 & 68,63 \\
\hline Phân ly & 10 & 19,61 & 12 & 23,53 & 29 & 56,86 \\
\hline
\end{tabular}




\begin{tabular}{|c|c|c|c|c|c|c|}
\hline Lệch lạc NC & 27 & 52,91 & 18 & 35,29 & 6 & 11,76 \\
\hline Tính cách nữ & 49 & 96,08 & 2 & 3,92 & 0 & 0,00 \\
\hline Paranoia & 36 & 70,59 & 13 & 25,49 & 2 & 3,92 \\
\hline Suy nhược & 7 & 13,73 & 28 & 54,90 & 16 & 31,32 \\
\hline Tâm thần phân liệt & 13 & 25,49 & 27 & 52,94 & 11 & 21,57 \\
\hline Hưng cảm nhẹ & 31 & 60,78 & 19 & 37,25 & 1 & 1,96 \\
\hline Hướng nội xã hội & 19 & 37,26 & 18 & 35,29 & 14 & 27,45 \\
\hline
\end{tabular}

Để đánh giá nhân cách trong các bệnh lý tâm thần các nhà khoa học trên thế giới sử dụng nhiều thang diểm để đánh giá trong đó thang điểm MMPI là được sử dụng nhiều nhất. Bệnh nhân co giật chức năng được đánh giá bằng thang điểm MMPI được thể hiện ở các thang trầm cảm $(68,63 \%)$, thang nghi bênh $(62,75 \%)$ và thang phân ly $(56,86 \%)$. Ngoài ra nét tính cách bệnh lý ở co giật chức năng còn thể hiện ở các thang suy nhược $(31,32 \%)$, thang hướng nội xã hội $(27,45 \%)$ và thang tâm thần phần liệt $(21,57 \%)$. Đăc điểm tính cách của co giật chức năng theo MMPI thể hiện ở 10 thang điểm, đặc biệt là không có điểm số bệnh lý nào của bệnh nhân ở thang điểm tính cách nữ [8].

Bảng 3.14. Đặc điểm kêt quả điều trị ỏ bệnh nhân nghiên cứu

\begin{tabular}{|c|c|c|}
\hline Liệu pháp & $\begin{array}{c}\text { Chỉ thống kế lượng } \\
\text { (n) }\end{array}$ & $\begin{array}{c}\text { Tỷ lệ } \\
\text { (\%) }\end{array}$ \\
\hline Hóa dược & 8 & 15,69 \\
\hline Hóa dược và sốc điện & 43 & 84,31 \\
\hline
\end{tabular}

Hiệu quả điều trị thể hiện ở số ngày điều trị, đa số bệnh nhân hết cơn co giật và không tái phát cơn sau 10 ngày điều trị. Phương pháp điều trị được sử dụng nhiều nhất là sốc điện cổ điển kết hợp với hóa dược $(84,31 \%)$. Sốc điện cổ điển đường áp dụng trên bệnh nhân với số lần từ 10-10 lượt cho một liệu trình điều trị. Số ít bệnh nhân dùng nguyên hóa dược: an thần và thuốc chống trầm cảm $(15,69 \%)$. Các thuốc an thần ở hống trầm cảm được dùng nhiều nhất là thuốc chống trầm cảm 3 vòng (Amitriptylin) với liều lượng là $135,73 \mathrm{mg}$. Điều này phù hợp với các nghiên cứu của Bùi Quang Huy (2017) cho rằng cần phải điều trị bằng thuốc chống trầm cảm, an thần kết hợp với sốc điện để điều trị nhằm phá võ ổ hưng phấn trên vỏ não của bệnh nhân [5].

\section{KẾT LUẬN}

1. Đặc điểm lâm sàng co giật chức năng. Trong nghiên cứu của chúng tôi thấy rằng nhóm tuổi bị co giật chức năng cao nhất là nhóm $<20$ tuổi $(68,63 \%)$, thấp nhất là nhóm >30 tuổi $(5,88 \%)$ và tỷ lệ nam/nữ là $1,7 / 1$.

Hoàn cảnh khởi phát cơn co giật chức năng sau sang chấn tâm lý chiếm tỳ lệ cao nhất
84,31\%; hình thái co giật chức năng chủ yếu là co giật toàn thân không có tính chất định hình (76,47\%).

Trong nghiên cứu của chúng tôi, triệu chứng co giật toàn thân là hay gặp nhất $58,82 \%$; còn co giật cục bộ chiếm $41,18 \%$. Thời gian diễn ra cơn co giật chức năng trung bình là 23,47 \pm 12,16 phút.

2. Một số đặc điểm nhân cách của bệnh nhân co giật chức năng. Sang chấn tâm lý gặp nhiều nhất là các sang chấn trong công việc $(41,86 \%)$, tiếp đó là sang chấn trong gia đình (25,58\%). Có tới 52,94\% bệnh nhân có nét tính cách yếu như là hiên khô, hay khóc, mít ướt, thường xuyên bị mọi người bắt nạt, ít có phản kháng tự vệ của bẻn thân. Còn tại thời điểm hiện tại các nét tính cách cảu bệnh nhân rất đa dạng phong phú: nét tính cách hay gặp lần lượt là cởi mở, nhút nhát, đại khái với $70,59 \%, 56,86 \%$ và $60,78 \%$.

Với trắc nghiệm tâm lý Eysenck thì bệnh nhân co giật chức nắng có chức năng hướng ngoại cao nhất với $54,90 \%$ và nét tính cách không ổn định chiếm tỷ lệ $74,51 \%$. Đăc điểm tính cách của co giật chức năng theo MMPI thể hiện ở 10 thang điểm, được thể hiện rõ rệt ở các thang trầm cảm $(68,63 \%)$, thang nghi bệnh $(62,75 \%)$ và thang phân ly $(56,86 \%)$.

3. Hiệu quả điều trị ở bệnh nhân co giật chức năng. Hiệu quả điều trị thể hiện ở số ngày điều trị, đa số bệnh nhân hết cơn co giật và không tái phát cơn sau 10 ngày điều trị. Phương pháp điều trị được sử dụng nhiều nhất là sốc điện cổ điển kết hợp với hóa dược (84,31\%).

\section{TÀI LIẸU THAM KHẢO}

1. Vonderlin R., Kleindienst N., Alpers G.W., et al. (2018), "Dissociation in victims of childhood abuse or neglect: a meta-analytic review", Psychol Med; 48(15): 2467-2476.

2. Dmytriw A.A. (2015), "Gender and sex manifestations in hysteria across medicine and the arts", Eur Neurol; 73(1-2): 44-50.

3. Tsuang MT, Van Os J, Tandon R, et al. (2013), "Attenuated psychosis syndrome in DSM-5", Schizophr Res; 150(1): 31-5.

4. Doernberg E. and Hollander E. (2016), "Neurodevelopmental Disorders (ASD and ADHD): DSM5, ICD-10, and ICD-11", CNS Spectr; 21(4): 295-299. 
5. Bùi Quang Huy (2017), "Rối loạn lo âu", Nhà xuất bản $Y$ hoc, Hà Nôii.

6. Asadi-Pooya A.A. (2017), "Psychogenic nonepileptic seizures: a concise review",Neurol Sci; 38(6): 935-940.

7. Dayan J. and Olliac B. (2010), "From hysteria and shell shock to posttraumatic stress disorder: comments on psychoanalytic and neuropsychological approaches", ] Physiol Paris; 104(6): 296-302.

8. Rowiński T., Kowalska-Dąbrowska M., Strus W. et al. (2019), "Measurement of pathological personality traits according to the DSM-5: A Polish adaptation of the PID-5. Part II empirical results", Psychiatr Pol; 53(1): 23-48.

\section{GÂY MÊ HỒI SỨC CHO BỆNH NHÂN Có KHOẢNG QT KÉO DÀI}

\section{TÓM TẮT}

Khoảng QT kéo dài được đinh nghĩa là: QTc > 480 ms đối với nữ và > 470ms đối với nam, trong đó QTc là QT hiệu chỉnh được đo trên điện tâm đồ Khoảng QT kéo dài được chia thành 2 nhóm là hôi chứng QT kéo dài bẩm sinh và khoảng QT kéo dài mắc phải. Cả 2 loai đều có thể dấn đến rối loai nhip nguy hiểm là xoắn đỉnh, trong điều kiện thuận lợi. Nễu bểnh nhân mang rối loạn nhị này phải gây mể phẫu thuật thì nguy cơ xoắn đỉnh là rất cao. Hiện nay chưa có khuyến cáo cu thể về gây mê hồi sức cho bênh nhân có khoảng QT kéo dài. Trên cơ sở sinh lý bệnh của hội chứng, cơ chế tác dụng của các thuốc dùng trong gây mê, tác động của phương pháp vô cảm đến dẫn truyên cớ tim, đồng thời xem xét lại y văn, chúng tôi muốn phân tích và đưa ra một số khuyến cáo về việc sử dụng thuốc, các lưu ý trong giai đoan trước, trong, sau mổ nhằm bảo đảm an toàn tối đa cho những bệnh nhân mang rối loạn nhịp này.

Từ khóa: Gây mê hồi sức, hội chứng QT kéo dài, xoắn đỉnh

\section{SUMMARY \\ ANESTHESIA AND RESUSCITATION FOR PATIENTS WITH PROLONGATION OF QT INTERVAL}

Prolongation of QT interval is defined as: QTC > $480 \mathrm{~ms}$ for women and $>470 \mathrm{~ms}$ for men, where QTc is the corrected QT that is measured on the electrocardiogram. Long QT interval is divided into 2 groups: congenital long QT syndrome and acquired prolongation of QT interval. Both types can lead to the dangerous arrhythmia - torsades de pointes whenever favorable conditions. If a patient with this arrhythmia requires anesthesia for sugery, the risk of torsade de pointes is very high. There are currently no specific recommendations for general anesthesia for kind of patients. On the basis of the pathophysiology of the syndrome, the mechanism of action of drugs used in anesthesia, the impact of anesthesia methods on myocardial conduction, and also reviewing the

\section{${ }^{1}$ Trường Đại học Y Hà Nội}

Chiu trách nhiếm chính: Phạm Quang Minh

Email: quangminhvietduc@yahoo.com

Ngày nhận bài: 7.5.2021

Ngày phản biện khoa học: 24.6.2021

Ngày duyệt bài: 6.7.2021

\section{Phạm Quang Minh ${ }^{1}$}

literature, we would like to analyze and give some recommendations on the use of drugs, specifically notes in the peri-operation to ensure optimal safety for these kind of patients.

Keywords: Anesthesia, long QT syndrome, torsades de pointes

\section{I. ĐĂT VẤN ĐỀ}

Sau sự kiện cầu thủ người Đan Mạch bị đột quy khi đang thi đấu. Ngay lập tức, các bác sỹ chuyên khoa tim mach đã tìm hiểu nguyên nhân của tình trang này, một trong số các nguyên nhân là những rối loạn nhịp tim "nguy hiểm". Các rối loạn nhịp tim loại này thường không hoặc ít có biểu hiện lâm sàng, khó phát hiện trên điện tâm đồ nhưng có thể biến chuyển thành những rối loạn nhịp nghiêm trọng, gây tử vong trong một số điêu kiện thuận lợi. Với đặc thù chuyên ngành Gây mê hồi sức, chúng tổi muốn phân tích đến một khía cạnh khác, đó là khi những bệnh nhân mang rối loạn nhịp tim này cần gây mê để phẫu thuật thì cần chú ý những gì. Bởi lẽ thuốc mê, phương pháp gây mê và tác động của phẫu thuật là những yếu tố nguy cơ cao gây rối loạn nhịp nghiêm trọng trên những bệnh nhân đã có rổi loạn nhịp từ trước. Theo thống kê, các rối loạn nhịp "nguy hiểm" ngày càng tăng, ngoài rối loạn bẩm sinh thì rối loạn mắc phải chiếm tỷ lệ khổng nhỏ, việc chẩn đoán xác định đôi khi cần thăm dò rất chuyên sâu như xét nghiệm gen. Trong bài này chúng tôi tập trung vào phân tích một rối loạn nhịp tim khá thường gặp là khoảng QT kéo dài.

\section{II. ĐỊNH NGHĨA VÀ CHẨN ĐOÁN}

Độ dài khoảng QT hiệu chỉnh theo nhịp (QT corrected - QTc) được tính theo công thức Bazett: QTc $=$ QT/VRR. QTc thay đổi theo tuổi, giới tính. Khoảng QT kéo dài được định nghĩa là QTc > 470 ms đối với nam, > 480ms đối với nữ [1].

Các nhà lâm sàng chia rối loạn liên quan đến khoảng QT thành 2 loại: hội chứng QT kéo dài bẩm sinh (LQTS) và khoảng $\mathrm{QT}$ kéo dài mắc phải. Hơn 75\% bệnh nhân bị hội chứng QT kéo 